\title{
En tiempo de elecciones
}

\section{José María Tojeira}

Rector de la Universidad Centroaméricana "José Simeón Cañas"। UCA

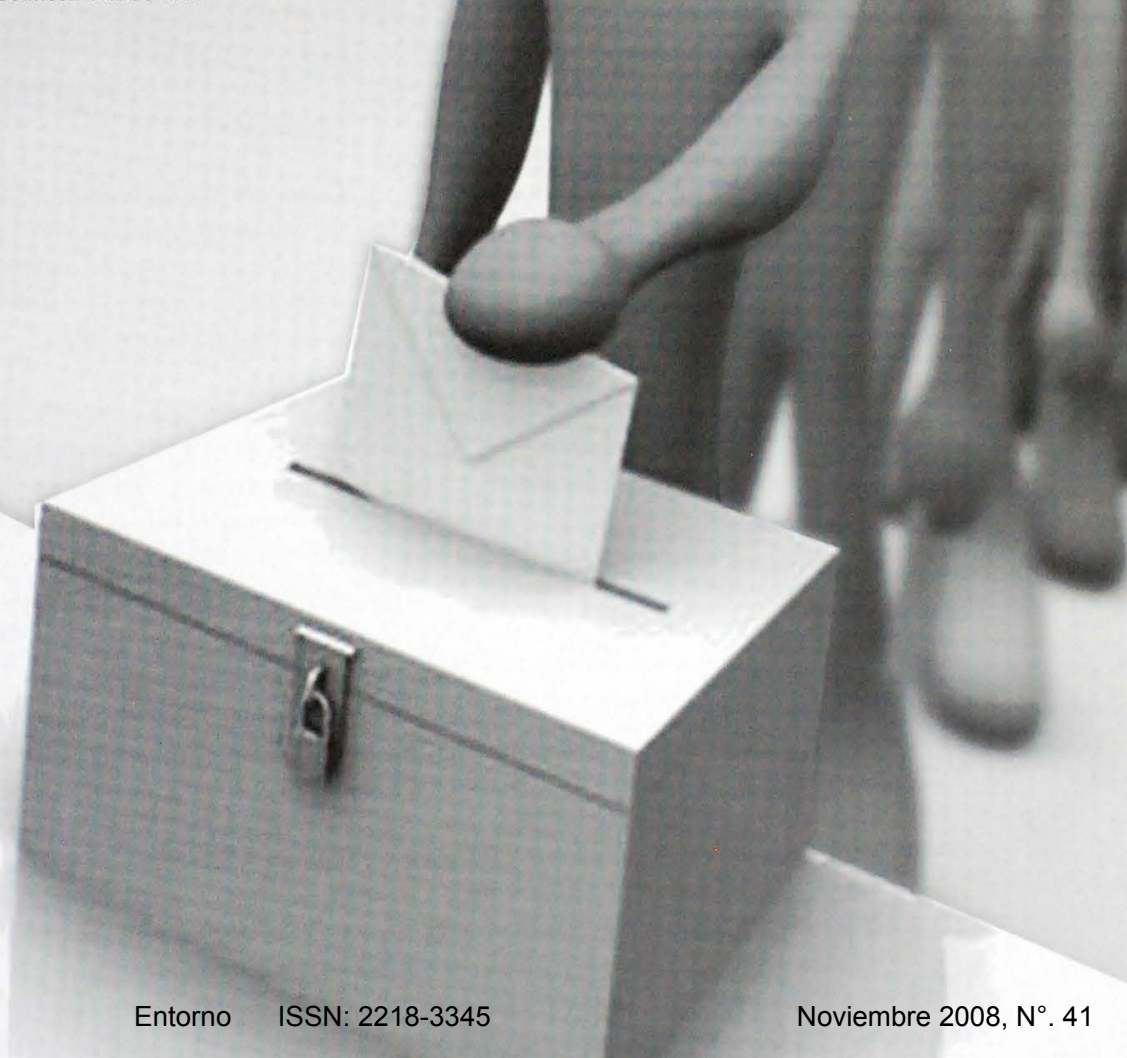




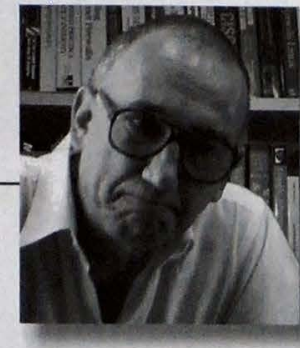

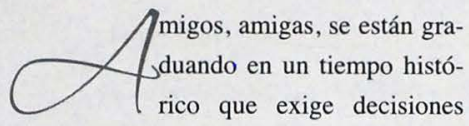

inteligentes para lograr un desarrollo social y un bienestar básico en el que participemos todos. Y también en un momento preelectoral, que es siempre una oportunidad para debatir los problemas a fondo, para encontrar los rumbos más apropiados, para allanar caminos hacia un futuro más justo y fraterno. Por eso es bueno que al mismo tiempo que reflexionamos sobre su graduación profesional, que los convierte en agentes y copartícipes de la construcción del futuro, reflexionemos sobre los necesarios temas de debate en estos momentos. No con el afán de hacer política partidaria sino con el deseo de compartir con ustedes, una vez más, el pensamiento de esta UCA que quiere siempre un desarrollo justo e integral para todos los salvadoreños.

En tiempo de elecciones todo el mundo trata de poner un nuevo rostro ante los electores. La derecha habla de reinventarse y la izquierda insiste en el cambio. Y es normal, porque desde hace tiempo las encuestas de opinión pública insisten en que la población afirma que el rumbo de El Salvador no es el adecuado. Muchos factores inciden en esta apreciación. Algunos profundamente subjetivos y nacidos de una sociedad consumista en la que estamos insertos,

que con frecuencia crea anhelos excesivos de poseer, o que establece expectativas de desarrollo viendo el nivel de vida de los parientes que viven en Estados Unidos. Otros factores, en cambio, son más objetivos y se centran en problemas como el alza fuerte y reciente en el costo de la vida, el desempleo (49\%), la enorme brecha en el ingreso entre quienes tienen más y quienes tienen menos, o la falta de protección social para grandes sectores de la población en el campo de la salud, las pensiones, etc. Algunos tratan de revertir este tipo de opinión insistiendo en lo bueno realizado hasta ahora. Sin embargo, aunque haya habido mejoría en algunos factores y situaciones, hay también situaciones y opciones de fondo de nuestra sociedad que no han mejorado en la que llamaríamos una dirección estructural. El modelo de desarrollo desigual, que privilegia la diferencia grave en el ingreso entre sectores pobres y ricos, está intacto. $\mathrm{Y}$ sigue generando diferencias de cincuenta a uno en los débiles extremos de la población. Incluso comparando el $20 \%$ de mayor ingreso con el $20 \%$ más desfavorecido, las diferencias son de 20 a uno. El doble de la diferencia que existen en los países desarrollados entre ambos sectores.

El gobierno insiste en su lucha contra la pobreza y en la reducción de la misma. Algunos proyectos como Red Solidaria son Noviembre 2008, N. 41 
encomiables. Pero la afirmación de que sólo un $30 \%$ de la población vive en pobreza, ya sumado incluso el $9 \%$ de pobreza extrema, no nos parece justa con nuestra realidad. En primer lugar porque el encarecimiento de los alimentos ha cambiado ya esas proporciones oficia- realidad salvadoreña. Podemos entonces hablar de una sociedad que tiene más de la mitad de su población, un $60 \%$, con carencias muy graves, en el caso de los totalmente excluidos, o serias, por lo menos, en los otros casos. La misma realidad de las pensiones o el Seguro Social,
“Un 21,1\% de nuestros hogares están simple y llanamente excluidos del desarrollo. Un 41,1\% tienen una exclusión relativa. En otras palabras no reciben todos los beneficios que en justicia le podría dar la sociedad."

les, pues el cálculo se hace en base al costo de la canasta básica de alimentos, y esta ha subido. Pero además hay otros modos de contemplar la realidad que me parecen más exactos y atinados. Un estudio del Departamento de Economía de la UCA, midiendo índices de exclusión de los beneficios básicos que nuestra sociedad debe brindar a los hogares salvadoreños, nos da los siguientes datos: Un $21,1 \%$ de nuestros hogares están simple y llanamente excluidos del desarrollo. Un $41,1 \%$ tienen una exclusión relativa. En otras palabras, no reciben todos los beneficios que en justicia les podría dar la sociedad, pero tienen la posibilidad tanto de pasar al nivel de inclusión y desarrollo, como de bajar a los niveles de exclusión absoluta. O quedarse en esa zona intermedia donde los sustos y las preocupaciones económicas son constantes, especialmente en estos tiempo de crisis internacional. Y finalmente, el $37,8 \%$ de nuestros hogares se puede decir que pertenecen al mundo de la inclusión plenamente, teniendo una seguridad y un bienestar adecuado a nuestra propia que no alcanzan a cubrir adecuadamente más que a una quinta parte de los salvadoreños, refuerza las conclusiones del estudio mencionado.

Frente a esta realidad, ustedes, profesionales tienen una enorme responsabilidad. Normalmente pasarán a formar parte del grupo de los incluidos. Y hay un cosa clara: si ese casi $40 \%$ de personas que forman el grupo de inclusión no trabaja ardua y responsablemente por incluir al resto en los beneficios del desarrollo, el $60 \%$ seguirá viviendo en una situación injusta, aunque algunos puedan salir de ella. Y esa situación de carencia sistemática y permanente seguirá pesando en nuestra propia convivencia, produciendo violencia, corrupción, individualismo, falta de cohesión social. Ya el papa Juan Pablo II advertía que sin confianza ciudadana no hay posibilidad de desarrollo. Y es difícil confiar cuando el mismo modo de funcionar de la sociedad produce pobreza y exclusión. Por eso también se necesita una gran generosidad para emprender caminos de cambio. 


\section{En tiempo de elecciones}

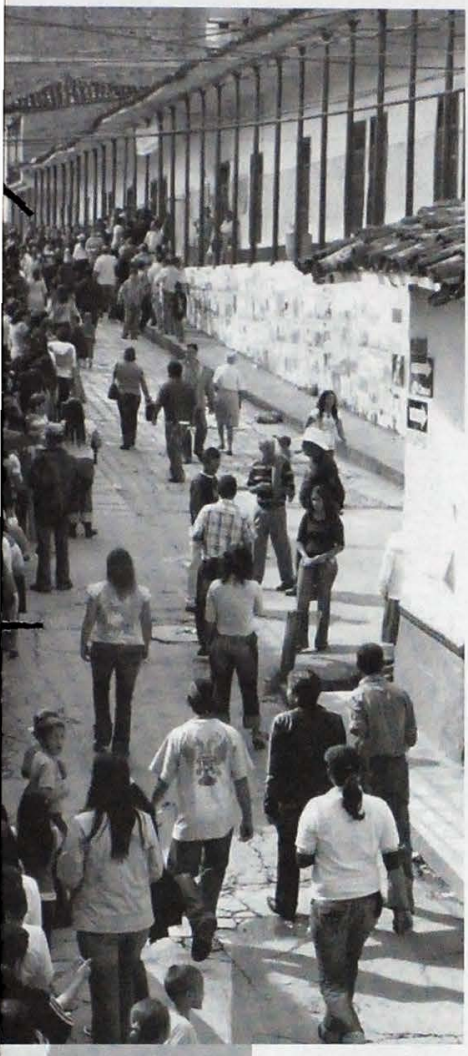

Porque hace falta ser creativo, trabajar más y mejor, e incluso sacrificar una parte de los propios beneficios mientras se apuesta por una convivencia social que ponga realmente como prioridad el bienestar de las grandes mayorías. El modelo de desarrollo desigual, que ha caracterizado nuestra historia a lo largo de más de 100 años, nos ha creado hábitos conformistas frente al dolor ajeno. El estilo de vida consumista, sin orientación ni controles éticos, nos impulsa a confundir el ser con el tener. Y aunque es cierto que la búsqueda de beneficio es inherente a sistema de libre mercado que debemos mantener, lo cierto es también que "cuando todo está en venta se diluye la cohesión social y el sistema se derrumba" (Jacques Delors, 19/05/08).

Cambiar este modelo de crecimiento desigual profundo, no es fácil. Pero debe ser una exigencia política tanto para las derechas como para las izquierdas. El Salvador necesita una transformación mental, un nuevo entendimiento entre todos los grupos sociales y políticos para construir unas relaciones sociales más incluyentes. Un cambio de mentalidad que nos conduzca hacia pactos sociales adecuados, manteniendo un espíritu de negociación permanente y una mirada abierta al mundo de los más necesitados.

$\mathrm{Y}$ de mentes abiertas a los pobres surgen exigencias muy concretas. Empezando por una nueva política fiscal, que debe ser dialogada y pactada con todos. Es una vergüenza que un país como el nuestro, con problemas graves de pobreza y exclusión, tenga una carga fiscal de solamente el $14 \%$ del PIB. Estados Unidos -el país al que tanto admiran tantos y tantas salvadoreños- recoge cerca del $30 \%$ de su PIB con los impuestos. Los países europeos recogen impositivamente hasta el $40 \%$ de toda la riqueza que producen para reinvertirla posteriormente en el ciudadano de modo equitativo. Y recogen mayor cantidad de dinero de quienes tienen más. No como nosotros, demasiado centralizados en el IVA, un impuesto que afecta más duramente a quienes tienen menos.

Con este modelo de impuestos no saldremos del desarrollo desigual que nos caracteriza, que al ser tan poco equitativo produce falta de cohesión social, emigración, violencia, cultura individualista del sálvese quien pueda, irrespeto a las leyes y desintegración familiar. El modelo de crecimiento desigual, que es el que existe realmente, independientemente del nombre que se le quiera dar el discurso, tiene que cambiar. Debe ser sustituido por un modelo de desarrollo equitativo, solidario, y por una verdadera economía social de mercado, de la que tanto se ha hablado y $\tan$ poco se ha impulsado en la realidad. No podemos esperar hasta el año 2021 para alcanzar en nuestra inversión en educación el $6 \%$ del PIB. El sistema de salud debe ser único y tratar adecuadamente a todas las personas. Y no dejar a las personas más pobres fuera del sistema, como pasa en la actualidad, por sólo poner un ejemplo, con los enfermos de Chagas, enfermedad de los más pobres y que sólo alguna gente generosa y aislada está tratando de combatir. Debe haber al menos 
una pensión compensatoria para los ancianos que han trabajado por el bienestar de El Salvador con muy poca recompensa económica y social, y que terminan sus años en el desamparo.

No podemos continuar diciendo que sólo viven en pobreza absoluta las familias que tiene menos de un ingreso de 161 dólares para cuatro personas, o en pobreza relativa aquellas que superando la cantidad mencionada no alcanzan el doble de la misma, 322 dólares. Los cálculos de pobreza no los hacen los que la sufren, sino aquellos que están en la inclusión, en general profesionales, que son parte del $40 \%$ que vive en el bienestar. Por eso la calificación de pobreza hay que calcularla de nuevo, escuchando a quienes más la sufren. Y la lucha contra la misma debe contar con más recursos. Tanto Arena como el FMLN, y el resto de los partidos, debían establecer un pacto que permita una acción de largo plazo y concertada que signifique mayor inversión en educación y en salud, dos factores que automáticamente generan mayor bienestar e incluso competitividad y riqueza. Son necesarios más pactos de empleo, de salario digno, de inversión en desarrollo. Pactos fiscales, pactos que lleven a reforzar las instituciones en vez de convertirlas en campo de competencia política. Los partidos políticos con facilidad pueden caer en el juego de la diferencias e incluso de la polarización. Partido viene de parte, $\mathrm{y}$ las partes siempre tienden a ser parciales. Pero los ciudadanos debemos exigir a esas partes, con frecuencia parciales, que miren más al bien común que a sus propios intereses partidarios. Ustedes, llamados a un liderazgo social y empresarial por la propia calidad de su educación, busquen unir y unirse frente a los problemas, que sólo juntos, y con buena voluntad de parte de todos, podemos resolver.

No tratamos aquí de hacer un plan de Gobierno, sino de insistir en responsabilidades sociales que a ustedes les tocará, desde sus propias disciplinas, afrontar en alguna medida y momento. Tampoco tratamos de inmiscuirnos en la contienda electoral, que debe ser limpia y de altura. Pero sí queremos recordarles a ustedes que tienen una profunda responsabilidad con El Salvador y que deben tenerla presente en sus propias responsabilidades laborales, asociaciones y grupos con los que se comprometan. Más allá de quién gane las elecciones, la responsabilidad de quienes tenemos una profesión liberal que nos incluye en el mundo de los privilegiados, es la de incluir a quienes consideramos hermanos y hermanas, hijos e hijas de una misma patria, en un tipo de sociedad que combata sistemáticamente la exclusión y propicie la solidaridad entre todos. Solidaridad que no debe ser entendida como una opción individual posible, sino como una necesidad social indispensable para el desarrollo y el bienestar.

No es tarea fácil, pero es necesaria. El mundo habla de una crisis alimentaria que puede durar hasta 15 años. De una crisis energética de largo plazo, de una crisis ecológica y medioambiental que no ha llegado todavía a sus niveles de mayor dificultad, y que exige grandes esfuerzos para que sea realmente reversible. La palabra prevenir -planificar el futuro teniendo en cuenta sus riesgos- es fundamental para salir de una situación como la actual, en la que las crisis pueden golpear mucho más duro de lo que imaginamos. Y todo esto sin mencionar nuestro propio riesgo

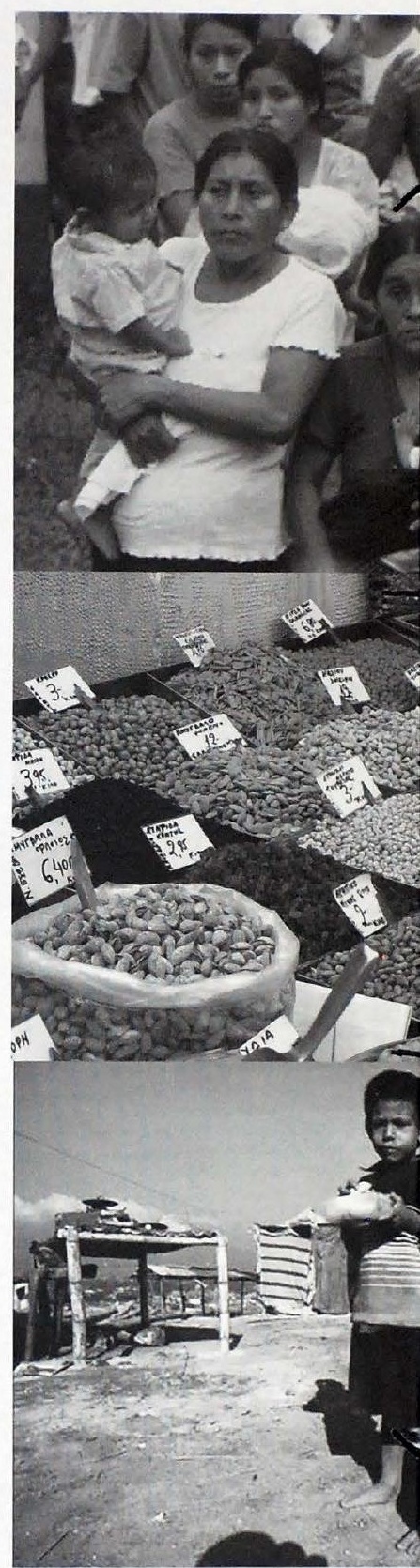

Noviembre 2008, $\mathrm{N}^{\circ} .41$ 
